\title{
APLICACIÓN DEL CONCEPTO DE "ARTE POPULAR" DE ARNOLD HAUSER A LA CERAMICA AZTECA
}

\section{Por Sonia Lombardo de Ruiz}

La posibilidad de detectar en el arte prehispánico de Mesoamérica la existencia de un arte popular, requiere una revisión previa de tipo teórico respecto al concepto mismo de arte popular, que permita verlo desde el punto de vista de los diferentes problemas que éste plantea, pues no es, ni con mucho, un concepto claro y preciso.

Buscar el arte popular en el ate mesoamericano, tampoco es una tarea fácil, primero, porque la investigación arqueológica, hasta hace algunas décadas, se concentraba en las áreas que contenían monumentos arquitectónicos importantes, dejando de lado las zonas habitacionales de la gente común, lo que proporcionaba una visión parcial de las sociedades antiguas; es hasta ahora, con los nuevos métodos arqueológicos, que se recoge una información más representativa de las sociedades en su totalidad; sin embargo, este tipo de trabajos es todavía escaso. En segundo lugar, se requeriría una revisión completa del material arqueológico y de las fuentes históricas, con la intención específica de diferenciar el arte popular del arte culto, y de buscar en dónde se pudiera situar el artista popular dentro de determinada estructura social.

En este pequeño trabajo, sólo se intentará dar una aproximación al problema y sondear en términos generales, las posibilidades de que pudiera existir un arte popular entre los aztecas, para después, siguiendo la definición que de él hace Arnold Hauser en su Introducción a la historia del arte, aplicarlo a la cerámica.

\section{Origen histórico del conceplo de arte popular}

Desde mediados del siglo xviri, se centró la atención de buena parte de los artistas, literatos y filósofos, en aspectos de la vida simple y natural, como una reacción ante la extrema artificialidad de la vida cortesana y al predominio del racionalismo de la Ilustración. Los temas campesinos y de la vida aldeana como formas ideales de existencia, que culminan con la sublimación del "buen salvaje", se introdujeron lícitamente como temas artísticos, y dieron paso en las artes plásticas a representaciones de costumbres y motivos populares o folclóricos, 
que fueron tomados durante el siglo xix por el Romanticismo y se convirtieron en una parte esencial de este movimiento.

El Romanticismo alemán a través de Herder y de los hermanos Grimm, principalmente, imprimió al concepto de pueblo o folk, un aspecto místico de mito nacionalista, en el cual subyacía la existencia de un "alma colectiva del pueblo", misteriosamente creadora, que generaba el arte popular, anónimo, expresión comunitaria y vigorosamente vital, lo que se conoció como la "teoría romántica" del arte popular.

La expansión colonialista europea amplió los horizontes del folklore a otras culturas y las producciones populares se vieron bajo la nueva luz de la etnología: la lingüística penetró en el significado de los símbolos; las teorías difusionistas vieron origenes comunes en los temas del folklore de los pueblos indoeuropeos, y el evolucionismo antropologico, que asumía que todas las culturas seguian el mismo proceso de desarrollo, condujo a la explicación de fenómenos artísticos de culturas avanzadas por comparación analógica con pueblos primitivos.

Más tarde, concretamente en las artes plásticas, Willensky, ${ }^{1}$ uno de los teóricos del movimiento moderno, preocupado por resaltar la trascendencia de la nueva concepción creadora, hace una revisión de las manifestaciones artísticas de la Europa Occidental, básicamente en el siglo xIx, y opone el concepto de "arte popular" como una categoría en el arte, antagónica a Ia de "arte original" definiendo al primero, como un arte no creativo, que sigue patrones dados, generalmente descriptivos.

Fisher, 2 dentro de la tendencia marxista, analiza la teoría romántica del arte popular y encuentra en este arte una variedad de expresiones de clases y condiciones sociales distintas, obra de individuos de diversos grados de talento e integridad, que echan por tierra el concepto del "alma del pueblo". Explica la idea romántica del arte popular, como una reacción a la desintegración social producida por el modo de producción capitalista y por la Revolución Industrial, que encuentra en los cantos y arte populares y en el folklore, la expresión de una comunidad homogénea y orgánicamente integrada, más allá de las divisiones de clase.

La corriente sociologica por su parte, ha intentado explicar el arte 1950.

1 Willensky, R. H. The Modern movement in art. Faber \& Faber, Great Britain,

2 Ernst, Fischer. La necesidad de arte. Ed. Unión, La Habana, 1964, Col.' Arte y Sociedad. 
popular con base en la relación de clases sociales y dentro de ella sobresale la obra de Arnold Hauser, ${ }^{3}$ porque desde este punto de vista, construye una teoría que recoge casi todos los problemas que presenta el arte popular y los integra dentro de una estructura bastante clara y unitaria.

En general, excluyendo la teoría romántica del arte popular que obedeció a una circunstancia histórica concreta, dentro de la problemática que éste planteó, todos los aspectos que pudieran ser aplicados a las artes plásticas prehispánicas, son susceptibles de ser agrupados, para fines metodológicos, en dos grandes campos: el social y el estético.

\section{El problema estético en el arte popular}

Muchos de los temas en discusión sobre el arte popular ponen en duda su capacidad para producir en el espectador una emoción estética, cualidad que es a su vez definitiva para considerarlo, o no, arte.

Se ha definido el arte popular como una producción anónima, tradicionalista y conservadora, que mantiene métodos, motivos y formas heredadas. También se ha dicho que el artista popular es poco creativo, porque trabaja dentro de su propia experiencia familiar, o la de una comunidad reducida, sin eriquecerla, y que sus trabajos son generalmente derivativos, descriptivos o sentimentales en su carácter. ${ }^{4}$

El arte genuino, el arte en sentido estricto, es el que amplía la experiencia del artista y de su grupo social, y se enfrenta con los problemas vitales y existenciales. La vivencia de una verdadera obra de arte, no la produce nunca el arte popular, sino la esfera más elevada de la actividad creadora; éste es apenas algo más que juego y ornamento. ${ }^{5}$

Por otro lado, la individualidad creadora es un factor preponderante en el desenvolvimiento histórico y las direcciones estilísticas. La personalidad del artista como creador, aunque está condicionada psicológica y sociológicamente por su medio, es definitiva para la orientación de las tendencias artísticas. En el anonimato del arte popular, la influencia del individuo se reduce a un mínimo y su actividad creadora está determinada no sólo por su relación con los modelos que encuentra ya

8 Arnold, Hauser, "Historia del arte según los estratos culturales: arte del pueblo y arte popular", en Introducción a la historia del arte. Ed. Guadarrama. Madrid, $2^{3}$ Ed., pp. 363-477.

4 Willensky, op. cit.

$\checkmark$ Hauser, op. cit. 
dados y los sigue, a la zaga de las clases superiores, sino también por su dependencia de los criterios del gusto en el grupo. 6

En el arte popular la producción es espontánea, el artista no es consciente de estar haciendo arte y por ello carece de criterios estéticos y de crítica. Sin embargo, aunque el artista del pueblo adopta motivos tradicionales, no los reproduce automáticamente, sino que los selecciona en base a ciertos principios en los que se manifiestan el gusto propio y el característico sentimiento formal del pueblo. ${ }^{7}$

Este último punto de vista parece ser el más importante, dentro de lo estético, pues le concede al arte popular cierta autonomía expresiva, manifiesta en sus composiciones, las cuales no pocas veces han retroalimentado al arte culto.

Así, un estudio de la plástica popular, debería registrar los principios formales según los cuales el pueblo conforma los motivos que recibe, para poder definir sus propias categorias formales; sumamente ilustradora en este aspecto es la investigación realizada por Béla Bartók en relación a la música popular húngara, en la cual descubrió como la principal invariante, la utilización de una escala pentáfona arcaica de origen oriental. 8

Un estudio de este tipo para el arte azteca, rebasa los alcances del presente artículo, pero queda abierta la posibilidad de hacerlo en base a material obtenido por excavación arqueológica que permita conocer el sitio de procedencia. El riquísimo acervo de piezas escultóricas, por ejemplo, permitirá analizar la expresión plástica a partir de los modelos estilísticos de las clases ilustradas con iconografía simbólica conceptual -producto de la especialización sacerdotal o del refinamiento palaciegosiguiéndolas en su proceso de popularización, tendiente a representaciones más directamente ligadas a vivencias de la realidad diaria de la gente común. ${ }^{2}$ Aquí, en cambio, se podrá dar un mayor acercamiento al problema, desde el punto de vista sociológico, apoyándose en las fuen-

6 lbid.

7 Ibid.

8 Béla Bartók. Die Volksmusik der Wagyaren und der benachbarten Volker, 1935, Apud. Arnold Hauser, op. cit., p. 389.

9 Una experiencia de este tipo inició la maestra Marta Foncerrada de Molina en el Seminario de Arte Prehispánico de la Facultad de Filosofía y Letras de la UNAM (1975), y los resultados comenzaron a verse, por ejemplo, en la diferencia estilística de las representaciones de la diosa Centéotl o diosa de los mantenimientos -la Ceres mexicana como la llama Sahagún- mucho más popular que lo que pudiera haber sido la Coatlicue, que era la tierra en un concepto más abstracto. 
DOI: http://dx.doi.org/10.22201/iie.18703062e.1976.45.1022
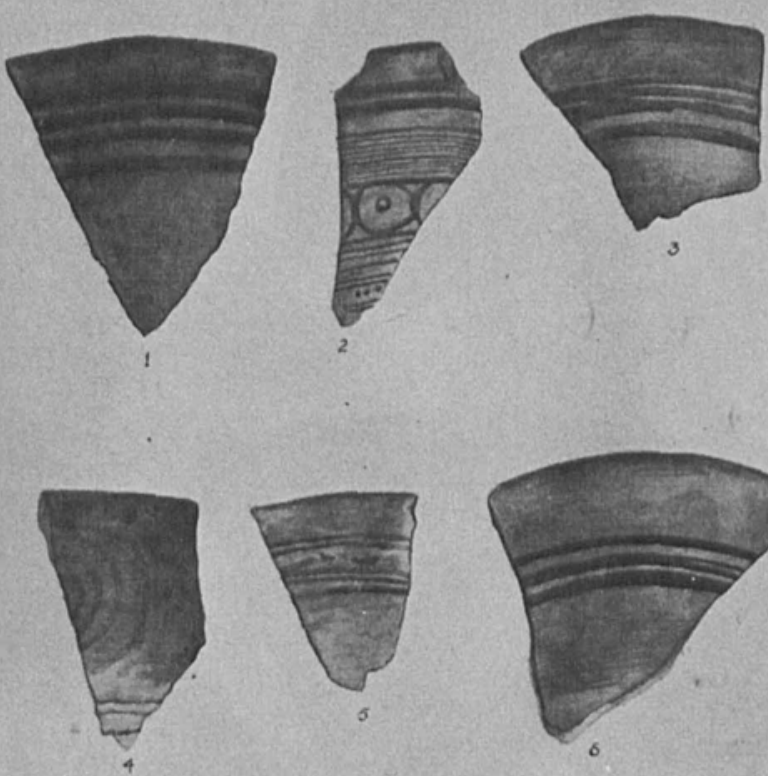

5
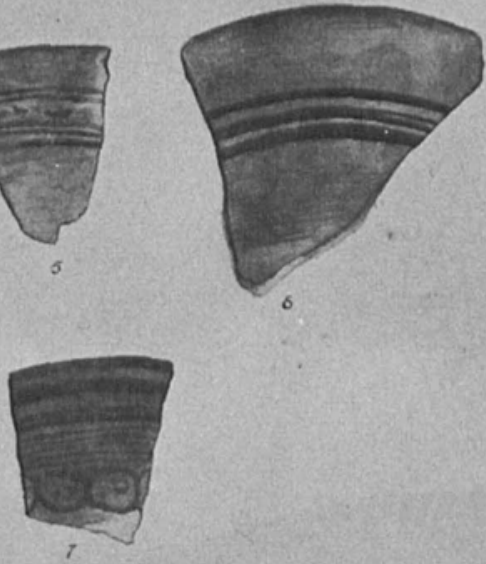

Decerwen mere saber fonde celer ndurd di barre Crupo III usu- Bees, Comie
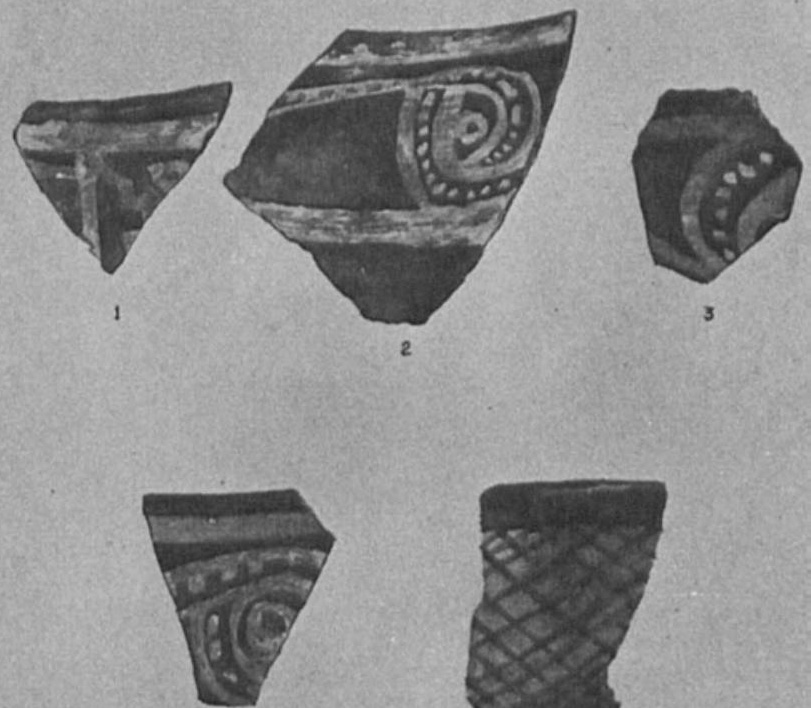

4

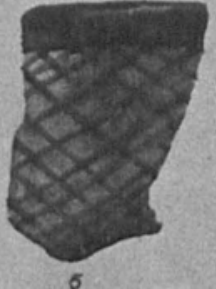

Ceramica plicromada aztece Decoración omarilla sabre fondo ro\% 
DOI: http://dx.doi.org/10.22201/iie.18703062e.1976.45.1022
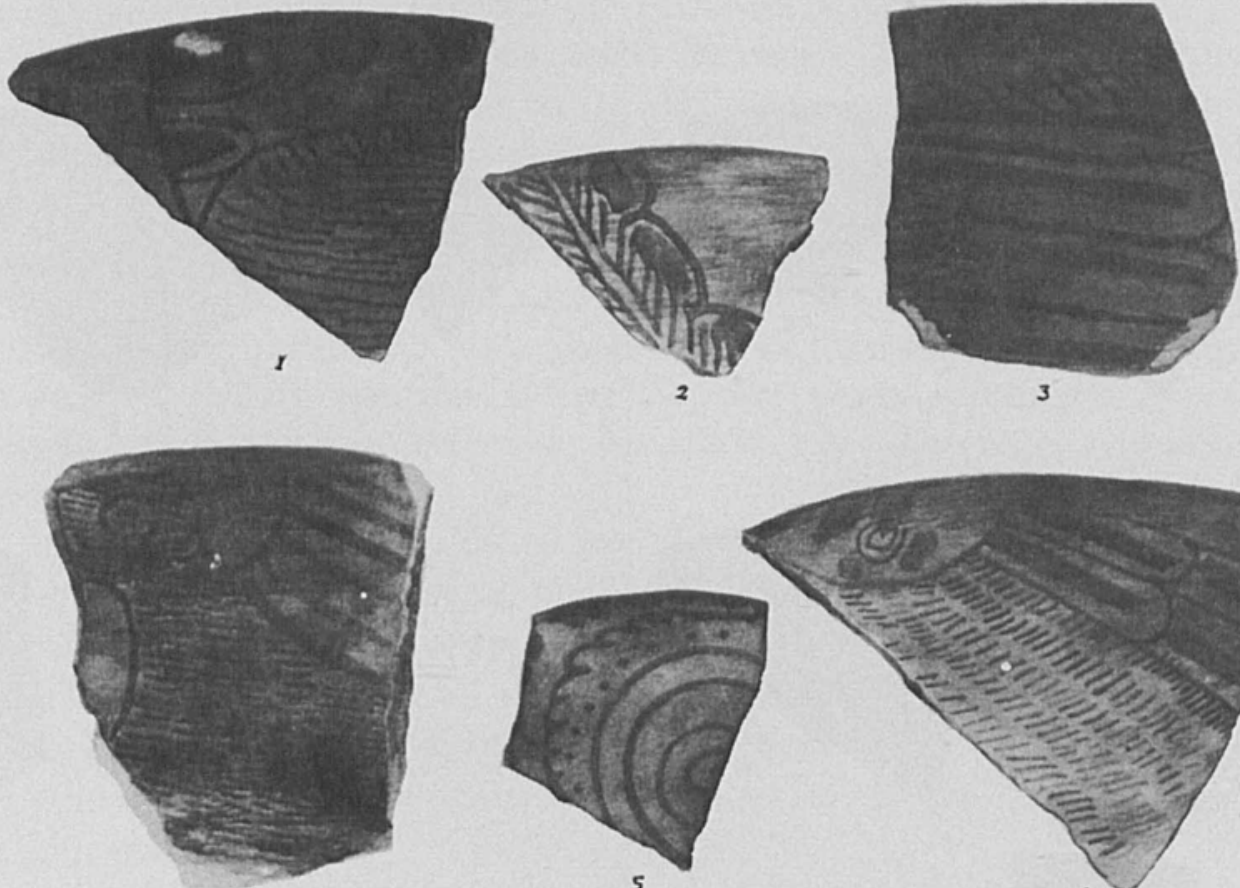

4
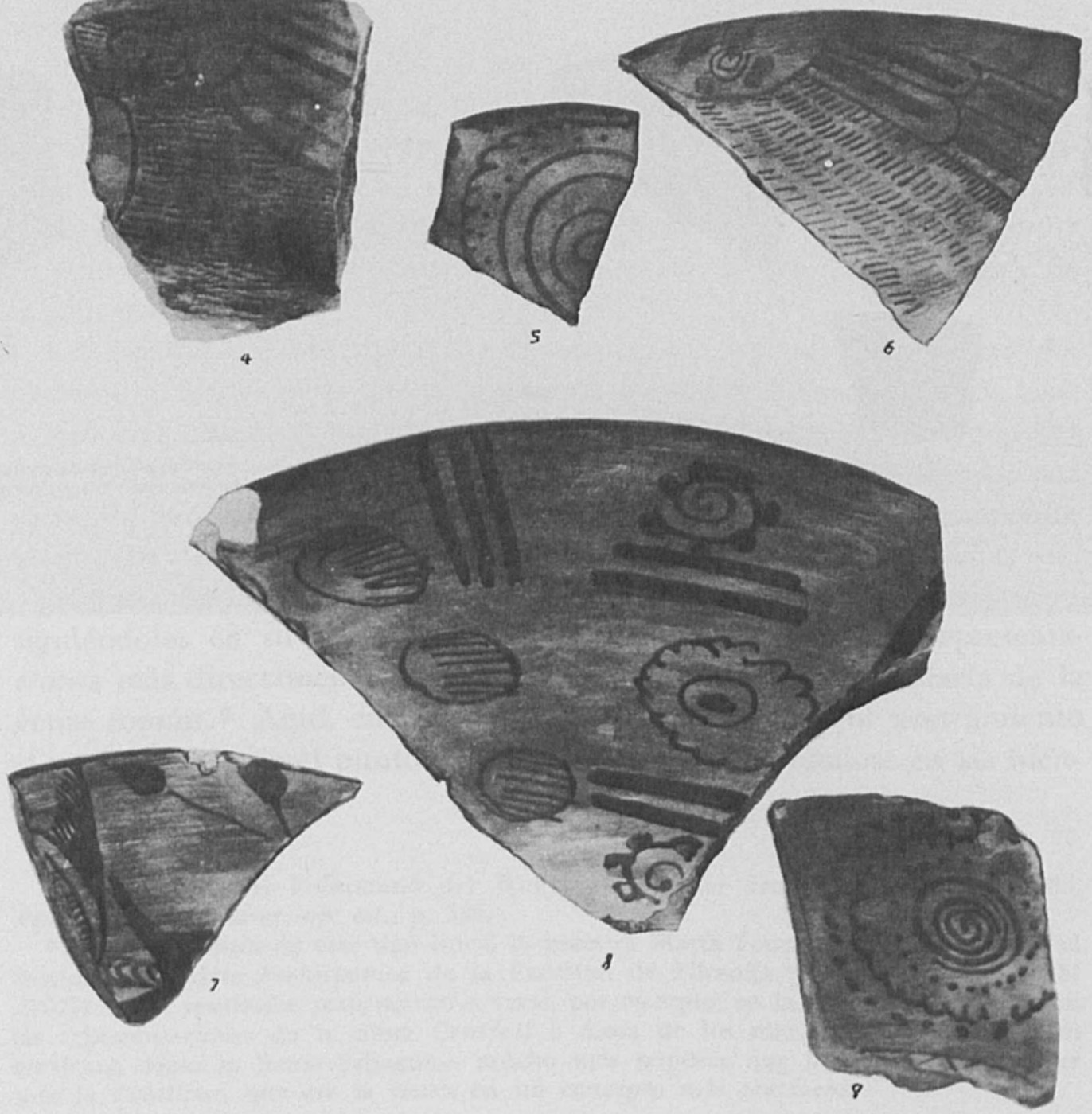

2. Fragmentos de cerámica del tipo Azteca IV. 
DOI: http://dx.doi.org/10.22201/iie.18703062e.1976.45.1022
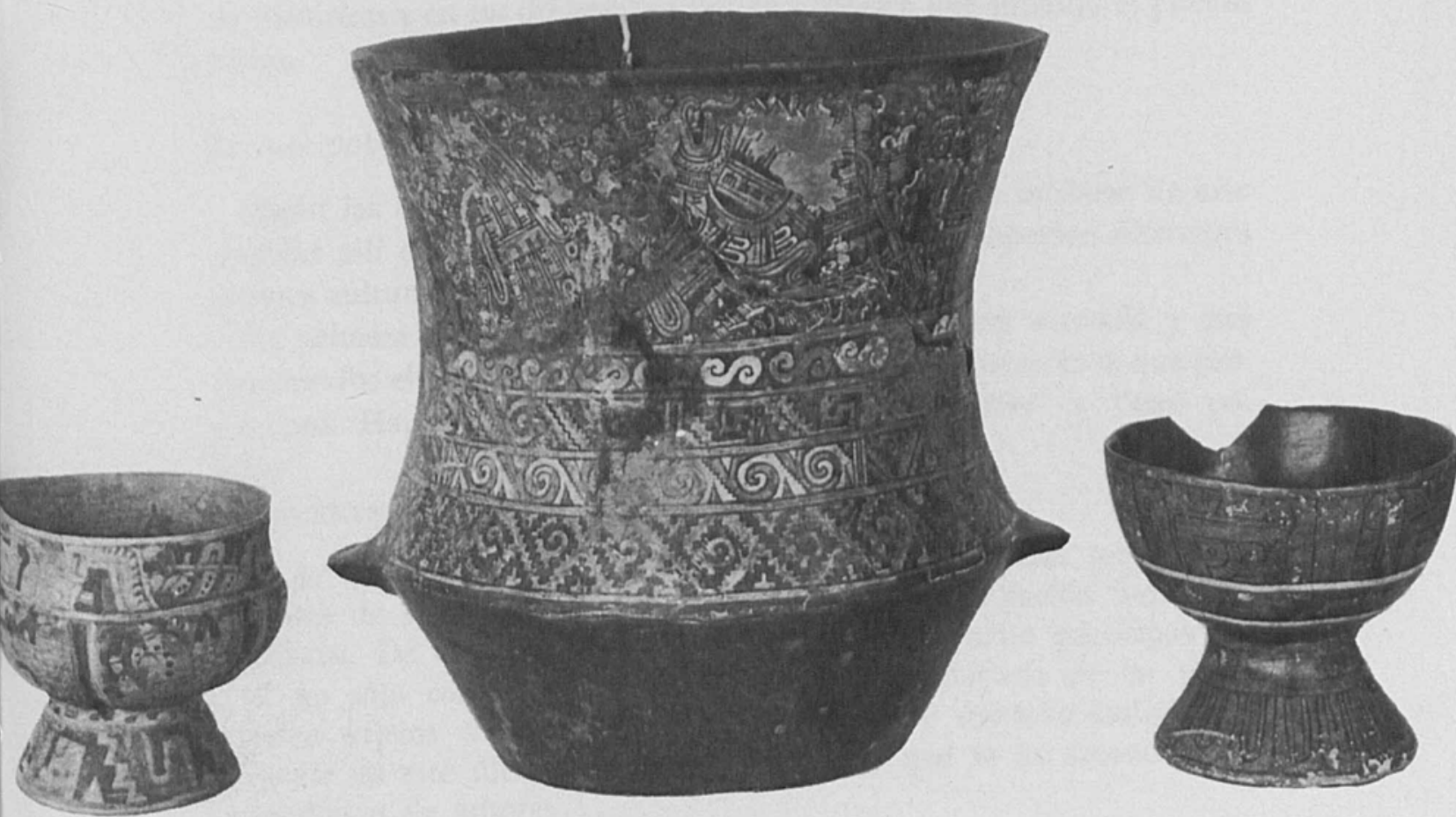

3. Cerámica encontrada en Excavaciones del Templo Mayor de México-Tenochtitlan. La vasija del centro, de tradición mixteco poblana, tiene decoración polícroma sobre estuco. 
DOI: http://dx.doi.org/10.22201/iie.18703062e.1976.45.1022 
tes históricas y en los diferentes tipos de cerámica que produjo el pueblo azteca.

\section{El arte popular azteca desde el enfoque sociológico}

Según las teorías sociológicas del arte, ${ }^{10}$ sólo puede hablarse de arte popular alli donde existen diferencias de clase que soporten diferentes estratos culturales.

La primera diferenciación de tipo social que parece acertada y que circunscribe el problema a un tipo especifico de sociedades, es la que proporciona Hauser al distinguir entre "arte del pueblo" y "arte popular".

Considera como arte del pueblo:

... la actividad poética, musical y plástica de estratos sociales carentes de ilustración y no pertenecientes a la población industrial urbana. De esencia: en este arte es que sus soportes participen de él no sólo como sujetos receptivos, sino, la mayoría de las veces como sujetos creadores, a pesar de que no se destacan individualmente en este último sentido ni pretenden que se les reconozca su condición de autores...

En cambio, entiende por arte popular:

... la producción artística o seudoartística que responde a las exigencias de un público predominantemente urbano, semiilustrado y tendente a la masificación. En el arte del pueblo productores y consumidores apenas están separados entre sí, y los límites entre ambos grupos son siempre fluctuantes; en el arte popular en cambio nos sale al paso un público improductivo artísticamente $y$ pasivo en lo esencial, y una producción profesional orientada exclusivamente a la demanda. Por muy significativo que sea, que el arte del pueblo, y especialmente la poesía del pueblo surge del seno de los mismos que gozan de él, mientras que, en cambio, las canciones populares - coplas y cuplés- proceden de compositores profesionales que pertenecen a las clases superiores y continúan dependientes de ella; la diferencia decisiva entre ambas clases de arte consiste en que el público es distinto en cada caso... ${ }^{11}$

Antes de proseguir al análisis de estos dos tipos de arte y de intentar identificarlos dentro de la producción cultural de los aztecas, es nece-

10 Hauser, op. cit., y también Fischer, op. cit.

11 Hauser, pp. 360-370. 
sario mencionar otras dos variantes artísticas, diferenciadas por Hauser y que frecuentemente se confunden con las dos anteriores.

Dentro del pensamiento de este autor, en las sociedades neolíticas de carácter comunitario -o en su caso, de las aldeanas mesoamericanas-, no puede darse un arte popular; se trataría de una cultura campesina unitaria (no campesina dentro de una sociedad de clases, opuesta a la urbana), a cuya producción artística denominó "arte campesino".

La otra variante es la de "arte provinciano". Se trata de un arte conscientemente dependiente; es un arte que sigue los pasos de la zona nuclear de la cultura y se sobrepone a las tradiciones locales. En las áreas ocupadas por estados imperiales, se da claramente este arte provinciano. Entre los aztecas, sería por ejemplo toda la producción artística encomendada para el consumo de los principales de los señoríos dependientes de Tenochtitlan, que casi siempre se escogfan entre la alta nobleza, emparentada con el tlatoani, e imponían los formas de vida de la metrópoli como un signo de la soberanía sobre sus vasallos: los templos, los palacios, la cerámica, los ornamentos, etcétera. Sin embargo, diferencias ecológicas y tradiciones regionales llegaban a imprimirle matices distintivos; la arquitectura de Castillo de Teayo y de Cempoala serían buenos ejemplos del arte provinciano azteca.

Discriminado en principio el arte campesino y el arte provinciano, se analizará primero la posibilidad de que exista un arte del pueblo entre los mexica, lo que conduce a su vez a meditar sobre su estructura social, tema que también es polémico todavia.

Los estudios tradicionales sobre este tema, se pueden agrupar en dos sentidos: los que consideran, en base a Alonso de Zurita, a la sociedad azteca como una sociedad gentilicia (como Bandelier y Monzón), y los que la consideran, siguiendo a Sahagún, una sociedad dividida en clases (como Moreno, Katz y Olmeda); tal divergencia parece estar originada en parte, porque las fuentes se refieren a diferentes momentos de desarrollo de la sociedad azteca.

Ahora, dentro de los que se inclinan a la existencia de una división de clases, Moreno, ${ }^{12}$ por ejemplo, asienta que había fundamentalmente cuatro clases: guerreros, sacerdotes, mercaderes y el pueblo común; esto es, diferencia las clases por el tipo de actividad sin darle importancia a que, tanto en la "clase" guerrera, como en la sacerdotal o en la de

12 Manuel M. Moreno. La organización politica y social de los aztecas. México, UNAM, 1981 . 
mercaderes, había a la vez individuos que pertenecían a los plebeyos o macehualtin, o a en los nobles pipiltin.

Olmeda ${ }^{13}$ hace una interpretación de las clases sociales en base a su participación en la estructura económica y considera que en la sociedad azteca existía una estratificación social entre nobles y plebeyos, pero por su origen tribal -y en esto participa de la corriente gentilicia- estaban ligados por vinculos de sangre, y en conjunto eran privilegiados en oposición a la clase tributaria que serían los pueblos conquistados o mayeques. En general, su división en dos clases, los tributarios y los que no tributan, parece acertada, pero pierde de vista que dentro de los aztecas mismos, los macehualtin o plebeyos, aunque en diferente grado, eran también tributarios.

Para los fines que aquí se persiguen, el enfoque que proporciona Carrasco ${ }^{14}$ parece el más adecuado: considera que en la sociedad azteca existió una estratificación social, debida a la distribución desigual del poder, en la cual se produjeron una serie de estamentos que eran categorías sociales definidas legal y moralmente. Los estamentos se regían por rasgos precisos como la propiedad, el tributo, la participación política, religiosa o militar; la legislación, las reglas suntuarias, la organización política o ceremonial, etcétera, con una serie de interrelaciones complejas. Las clases sociales, definidas por su participación en la producción, se reducian a los pipiltin, que tenían derechos sobre tierras especiales trabajadas por otros individuos que les daban tributo y que tenían privilegios en la organización política, y a los macehualtin que eran los gobernados tributarios, cuyas tierras eran de propiedad comunal. Caso ${ }^{15}$ señala que antes de la guerra contra Azcapotzalco, Izcóatl, el caudillo guerrero, tuvo un convenio con los macehualtin en el que éstos aceptaron una distinción económica y de servidumbre a los pipiltin que se consideraban descendientes de los toltecas.

La estratificación vertical entre la nobleza, se debía a deferencias étnicas -entre mexicas y tlatelolcas por ejemplo- ya que existia la costumbre de establecer vinculos matrimoniales con principales de otros

13 Mauro Olmeda. Desarrollo de la sociedad mexicana. México, Mauro Olmeda Editor, 1966.

14 Pedro Carrasco. Participación verbal en el Seminario sobre la ciudad de México. Tenochtitlan, impartido por el Dr. Edward Calnek en el Centro de Investigaciones Superiores del Instituto Nacional de Antropología e Historia, julio-agosto 1975.

16 Alfonso Caso. "Instituciones indígenas precortesianas", en $L a$ política indigenista en Mexico. México, Instituto Nacional Indigenista, 1973, 2a. Ed., 4. 
señorios de rango, según el grado de parentesco con el tlatoani, que era la máxima jerarquía, o de tipo corporativo.

Muy relacionada con lo anterior y definitiva para distinguir el arte popular, es la ubicación de los artesanos y los comerciantes dentro de clases sociales, que vuelve a ser problemática y a presentar enfoques distintos.

Mientras unos autores, como Caso y Calnek, ${ }^{16}$ aceptan a la artesanía y al comercio como autónomos dentro de las fuerzas productivas de la estructura económica, Mauro Olmeda, con base en Cunow, ${ }^{17}$ sustenta que aunque estas actividades se daban en ciertos casos por especialización de tiempo completo:

No eran un exponente genuino de las relaciones de producción y de las fuerzas productivas, sino una creación económica artificial, nacida al amparo de la acumulación de la riqueza obtenida por la clase dominante del imperio azteca y que, como éste (el comercio) debe ser estudiado como un fenómeno de supraestructura a la que él mismo pertenece. ${ }^{13}$

Tal diferencia de criterios lleva a que se acepte en el primer caso a los comerciantes y artesanos, dentro de las relaciones de producción, como una "clase intermedia", y en el segundo, a la negación de que estos grupos constituyan una clase independiente.

Aunque el problema no es fácil, las fuentes que se refieren a los comerciantes indican que éstos no trabajaban las tierras, sino que pagaban su tributo en especie; que los había, tanto nobles y plebeyos, como ricos y pobres que no podian costear las ceremonias que les correspondian; también dicen que los comerciantes prósperos establecían alianzas matrimoniales con la nobleza. En este punto es importante seńalar que en la sociedad mexica, los dos únicos casos de movilidad social que se registran entre nobles y plebeyos, son el de estos comerciantes prósperos y el de los guerreros valientes; esto deja en claro los mecanismos de la aristocracia para integrar a su clase los dos tipos de fuerzas productivas más importantes para el imperio, las que promueven el comercio

16 Caso, Ibid., pp. 30-36. Calnek comunicación verbal en el Seminario sobre la ciudad de México-Tenochtitlan, en el Centro de Investigaciones Superiores del Instituto Nacional de Antropología e Historia, julio-agosto 1975.

17 Olmeda, op. cit, 58, cita y traduce literalmente un párrafo de la obra de Hein. rich Cunow Allgermeine Wirtschaftgeschichte, Berlín, 1926.

18 Olmeda, op. cit., 64 . 
y las que obtienen tributos por medio de la guerra. En cambio, nunca se mencionan ascensos de artesanos plebeyos a la clase aristocrática, pero sí existen claras evidencias de que las artesanías se enseñaban en el calmecac que era la escuela de los pipiltin y un significado texto de la Crónica Mexicáyotl, al hablar de la decadencia de Moctezuma Ilhuicamina dice que:

... habia tenido mucha progenie, por lo cual dijera "no todos mis hijos reinarán"; entonces les proporcionó la "ballesta" (tlauitolli), el arte de la lapidaria, la ebanisterfa, el pintamiento del lago, la escribanía: todos sus hijos se volvieron fiscales... ${ }^{10}$

Hasta donde está planteado el problema, parece lo más coherente, que existiera un artesano y un comercio a dos niveles, sin constituir por sí mismos una tercera clase social:

Entre los macehualtin, como actividades cotidianas compartidas con la labranza de la tierra, estaría la fabricación casera de jarcia, cerámica, textiles y muchos utensilios, de piedra y madera para el consumo familiar, o hasta cierta medida para intercambio comercial en base a trueque, como artículos de primera necesidad. Olmeda, 20 hace notar que la impresionante afluencia de gente a los tianguis, que describen los cronistas, se debía a la poca concentración de productos por personas intermediarias, lo que quiere decir que el comercio era una actividad al alcance de muchísima gente plebeya. Por lo que a la artesanía suntuaria se refiere, la de los joyeros y los tejedores de pluma o amanteca, es evidente que requería una capacitación técnica, una especialización de tiempo completo, una inversión en materia prima costosa -a veces importada de otras regiones- y un adecuado sistema de distribución, organizado con las debidas seguridades para su transporte; este tipo de comercio y de artesanía, era controlado por los pipiltin. Era también objeto de este comercio la mercancia acumulada por el tlatoani y los pipiltin como productos del botín de guerra y los tributos impuestos a los sometidos, que eran llevados a comisión por estos comerciantes pochteca, siendo su actividad sumamente productiva para su clase. Los comerciantes interregionales constituian, entonces, un estamento importante dentro de la clase gobernante, que realizaba las empresas comerciales por su cuenta, ofreciéndole al tlatoani una participación en forma de

19 Fernando Alvarado Tezozómoc. Crónica Mexicáyotl. México. Imprenta Universitaria, 1949.

20 Op. cit., 63. 
"regalos" o el producto de la venta de la mercancía que les habia sido encomendada. ${ }^{21}$

Volviendo al tema de arte, y a los dos conceptos de Huaser, "arte popular" y "arte del pueblo", se intentará ver cómo pudieran aplicarse a la sociedad mexica. En principio hay un escollo radical de carácter histórico, que es la diferencia esencial entre la urbe europea que sirvió de referencia a las categorías de Hauser, y la ciudad azteca; sin embargo, considerándolas a cada una en su género, así como a las dos sociedades, diferentes en su tipo, la terminologfa de Hauser puede ser utilizada.

Como arte del pueblo entraría la producción artesanal familiar, no especializada, realizada en horas de ocio de los chinamperos, como textiles, cerámica, objetos de uso diario, mobiliario, instrumentos de trabajo y hasta de culto doméstico, como incensarios y braseros, consumidos por los mismos productores; cabría aqui la decoración de canoas, remos, esteras, arcos, flechas, escudos, ofrendas votivas en los templos de barrio, etcétera. Pues debe recordarse que en sociedades en el estadio tecnológico de Tenochtitlan, cualquier hombre tenía la habilidad para fabricar muchos de los utensilios de uso común.

El arte popular sería, entonces, la producción realizada por artesanos especializados que se debieron dar - por ejemplo- en los santuarios como Tocititlan, en los templos de las parcialidades (que eran una especie de parroquias que controlaban varios barrios) $y$ aun en el Templo Mayor, para satisfacer el mercado de los devotos y peregrinos que venían a visitarlos. Este tipo de objetos era hecho en serie -una evidencia son las figurillas de dioses de barro hechas en molde-, para un público amplio, y las gentes que lo producian eran los aprendices de artesanos que habian en el calmecac. Siguiendo a Hauser, por su distribución y su consumo, éste es un caso claro de arte popular.

Su dependencia del arte culto se hace patente en que repite-retomando el ejemplo de los diosecillos de barro hechos en molde-, la forma iconográfica de representación, de acuerdo a las características que les ha impreso la alta jerarquía sacerdotal, al establecer, de acuerdo a la cosmogonfa por ellos concebida, los signos que denotan a cada deidad, para que la pequeña figurilla, imagen del dios, cumpla su función mágico-religiosa.

En la cerámica parece factible hacer una diferenciación de la pro-

21 Muchas de las características de los artesanos y comerciantes fueron tomadas de Caso, op. cit. 
ducción y el consumo dentro de las clases sociales, ya que existía, por costumbre, una distinción en la utilización de vajillas, según lo describe Sahagún ${ }^{22}$ cuando reseña los banquetes y ceremonias que ofreclan los comerciantes a su regreso de alguna expedición; en ella dice que a los pilli se les servía en un tipo de jícaras llamadas ayotectli y a los demás en jícaras de barro común. El tipo de cerámica conocida como azteca III (figura 1), con diseños negros sobre el color natural del barro, con formas de platos trípode, cajetes, molcajetes, etcétera, parecen ser, por su diseño sencillo de líneas finas en bandas y circulos concéntricos, el tipo de cerámica del pueblo, que tuvo un origen casero y se continuó haciendo con los mismos diseños tradicionales durante toda la ocupación tenochca, aunque existe la posibilidad de que al final se hiciera por artesanos especializados en los calpulli; pues debe recordarse que en cada uno de ellos existía un telpochcalli o colegio para plebeyos, ${ }^{23}$ en los que se realizaba trabajo comunal y que muchas veces se especializaban en algún oficio, lo que llevó a los cronistas a creer que se trataba de gremios; de todos modos, tanto los productores como el público que lo consumia, eran los macehualtin.

El tipo de cerámica policroma, denominada azteca iv (figura 2) que se caracteriza por la representación de sencillos motivos florales y zoomorfos -generalmente pájaros-, por su propia técnica policroma, implica un grado mayor de especialización artesanal, que se podía dar en la ciudad en los estamentos más bajos de los pilli; es esta cerámica la que podria llamarse arte popular. Aunque en ciertos aspectos como la orfebrería y el tejido de plumas hecho por los amanteca tenía fama el arte azteca y su demanda era extrarregional, parece que en la cerámica, lo que se utilizaba como "arte culto", que era un arte religioso, era más bien la cerámica importada, muy especialmente la de tradición mixteco-poblana, la cual tenía una extraordinaria calidad técnica y sus representaciones eran básicamente miticorreligiosas (figura 3). Esta costumbre podría explicarse, o por la existencia de grupos de artesanos especializados, de otras etnias, residentes en Tenochtitlan, que por su habilidad eran muy apreciados por la alta sociedad mexicana, ${ }^{24}$ o

22 Sahagún, Bernardino de, Historia general de las cosas de la Nueva España, libro Ix. México, Ed. Porrúa, 1956.

23 Motolinía. Memoriales, 1903, 44.

24 Al hacerse las excavaciones para la Línea 2 del Sistema de Transporte Colectivo (metro), en un área cercana y al suroeste de la iglesia del Salto del Agua, se localizó una fuerte concentración de tepalcates del tipo mixteco-puebla que permitió pensar en una agrupación de ceramistas foráneos. 
bien por comercio, teniendo en este caso el producto importado un valor especial de prestigio, que sobrepasaba el valor del producto local.

En conclusión, se puede decir que dado el grado de desarrollo urbano que alcanzó Tenochtitlan y la compleja estratificación de clases sociales que en ella se produjo, es factible diferenciar desde el punto de vista sociologico, un "arte del pueblo" y un "arte popular" en el sentido de Hauser, como dos tipos de arte distintos que tuvieron como soporte dos diferentes grupos sociales. La cerámica de uso diario, en sus dos estilos más generalizados pudo haber respondido a las dos clases de productores, los campesinos plebeyos y la población urbana de los bajos estratos de la nobleza, pero otro tipo de artes menores, como la pequeña escultura, la orfebreria, la plumaria, los textiles, etcétera, debieron regirse por relaciones mucho más complejas, determinadas por reglas suntuarias y ceremoniales, religiosas, politicas o militares, cuyo carácter popular o culto podría descubrirse con un acucioso estudio de las fuentes históricas y arqueológicas. 


\section{BIBLIOGRAFIA}

Alvarado Tezozómoc, Fernando. Crónica Mexicáyotl. México, Imprenta Universitaria, 1949.

Bandelier, A. F. "On the distribution and tenure of lands and the customes among the ancient mexicans", from the 11 Annual Report of the Peabody Musseum of Archaeology and Ethnology, Cambridge, 1879.

- "On the social organization and mode of government of the ancient mexicans". Twelfth Annual Report of the Trustees of the Peabody Musseum of Archaeology and Ethnology, Cambridge, 1879.

- - - "Des calpullis mexicaines, de leur administration, de leur origine et du principe communiste qu'ils impliquent", Congrés International des Américanistes, tomo primero, Bruselas, 1879.

Calnek, Edward. Seminario sobre la ciudad de México-Tenochtitlan, en el Centro de Investigaciones Superiores del Instituto Nacional de Antropologia e Historia, julio-agosto 1975 .

Carrasco, Pedro. Seminario sobre la ciudad de México-Tenochtitlan, en el Centro de Investigaciones Superiores del Instituto Nacional de Antropología e Historia, julio-agosto 1975.

Caso, Alfonso. "Instituciones indígenas precortesianas", en La politica indigenista en México. México, Instituto Nacional Indigenista.

"Folk Art" en Encyclopedia of World Art, vol. v, Mc. Graw Hill Pub. Co. Ltd., London.

Fischer, Ernest. La necesidad de arte. Ed. Unión, La Habana, 1964 (Col. Arte y Sociedad).

Hauser, Arnold. Introducción a la Historia del Arte. Ed. Guadarrama, Madrid, 1961. 2a. Ed.

Katz, Friedrich. "Las condiciones socioeconómicas entre los aztecas en los siglos xv y xvi", Letras Nuevas, Facultad de Filosofia y Letras, México, julio-agosto, 1958 .

Monzón, Arturo. El calpulli en la organización social de los tenochca. México, 1949.

Moreno, Manuel M. La organización politica y social de los aztecas. México, UNAM, 1931.

Motolinía, Memoriales, 1903.

Olmeda, Mauro. El desarrollo de la sociedad mexicana, La fase prehispánica. México, Mauro Olmeda Ed., 1966.

Sahagún, Fr. Bernardino de. Historia general de las cosas de la Nueva España. México, Ed. Porrúa, 1956. 
Willensky, R. H. The modern movement in art. Great Britain, Faber \& Faber, 1950.

Zurita, Alonso de. "Breve relación de los señores de la Nueva España", Nueva colección de documentos para la historia de México. México, Ed. Chávez Hayhoe. 